\title{
Effects of carbonization temperature on pore development in polyacrylonitrile-based activated carbon nanofibers
}

\author{
Hye-Min Lee, Kay-Hyeok An and Byung-Joo Kim* \\ R\&D Division, Korea Institute of Carbon Convergence Technology, Jeonju 561-844, Korea
}

\section{Article Info}

Received 21 February 2014

Accepted 18 March 2014

*Corresponding Author

E-mail: kimbj2015@gmail.com

Tel: $+82-63-219-3720$

\section{Open Access}

DOI: http://dx.doi.org/

10.5714/CL.2014.15.2.146

This is an Open Access article distributed under the terms of the Creative Commons Attribution Non-Commercial License (http://creativecommons.org/licenses/ by-nc/3.0/) which permits unrestricted non-commercial use, distribution, and reproduction in any medium, provided the original work is properly cited.

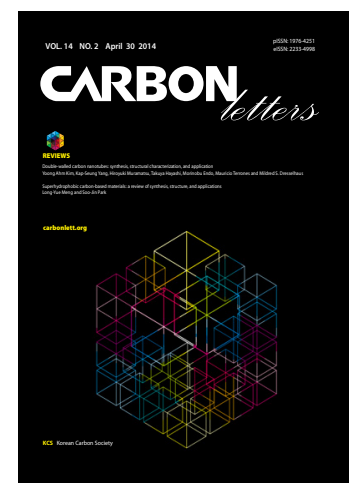

http://carbonlett.org

pISSN: 1976-4251

elSSN: 2233-4998

Copyright $\odot$ Korean Carbon Society

\begin{abstract}
In this work, activated carbon nanofiber (ACNF) electrodes with high double-layer capacitance and good rate capability were prepared from polyacrylonitrile nanofibers by optimizing the carbonization temperature prior to $\mathrm{H}_{2} \mathrm{O}$ activation. The morphology of the ACNFs was observed by scanning electron microscopy. The elemental composition was determined by analysis of X-ray photoelectron spectroscopy. $\mathrm{N}_{2}$-adsorption-isotherm characteristics at $77 \mathrm{~K}$ were confirmed by Brunauer-Emmett-Teller and Dubinin-Radushkevich equations. ACNFs processed at different carbonization temperatures were applied as electrodes for electrical double-layer capacitors. The experimental results showed that the surface morphology of the CNFs was not significantly changed after the carbonization process, although their diameters gradually decreased with increasing carbonization temperature. It was found that the carbon content in the CNFs could easily be tailored by controlling the carbonization temperature. The specific capacitance of the prepared ACNFs was enhanced by increasing the carbonization temperature.
\end{abstract}

Key words: carbon nanofibers, $\mathrm{H}_{2} \mathrm{O}$ activation, super-capacitor, carbonization temperature

\section{Introduction}

Super-capacitors, as energy storage devices with high power density and long cycle life, have attracted great attention in recent years because of their potential in applications such as portable devices, electric vehicles, transportation, and digital communication systems [1-3]. According to the energy storage mechanism used, super-capacitors can be divided into two classes. The function of electric double-layer capacitors depends on the pore structure of the electrode materials and that of pseudo-capacitors is based on active electrode materials in which the faradic redox process occurs. To develop super-capacitors with high performance, various materials have been examined as possible electrode materials. Among them, activated carbon powders [4,5] and fibers [6-8]; which have high porosity, a large surface area, and good conductivity, have been used most widely.

Activated carbon nanofibers (ACNFs) are well known as materials with a number of significant advantages over conventional powders. ACNFs are microporous carbonaceous adsorbents developed from organic precursors, by either physical or chemical activation [9-14]. The advantages of ACNFs are smaller fiber diameter, more concentrated pore-size distribution, and excellent adsorption capacity at low concentrations, in comparison with conventional activated granular or powdered carbons [11].

The type of porosity is mainly determined by the type of precursor employed; however, the method of activation is a key parameter which may influence the final pore-size distribution [15]. Carbonization temperature is another variable which has a large effect on porevolume evolution [15-17]. High carbonization temperature results in a greater amount of volatiles being released from the raw material, and eventually influences the product yield 
and porosity [16].

In this work, polyacrylonitrile (PAN)-based ACNF electrodes with high capacitance and good rate capability were prepared by optimizing the carbonization temperature prior to $\mathrm{H}_{2} \mathrm{O}$ activation

\section{Experiment Details}

\subsection{Sample preparation}

PAN nanofibers (Amotech, Korea) were used as the starting material. The nanofibers were heated to $800-1000^{\circ} \mathrm{C}$ at $5^{\circ} \mathrm{C} / \mathrm{min}$ in a $\mathrm{SiC}$ furnace under nitrogen $(99.999 \%)$, and kept at a target temperature for $2 \mathrm{~h}$ to obtain carbonized nanofibers. Then, the gas flow was switched to $\mathrm{H}_{2} \mathrm{O}$ at a rate of 0.5 $\mathrm{mL} / \mathrm{min}$ while the temperature was raised to $1000^{\circ} \mathrm{C}$ and held for $20 \mathrm{~min}$. ACNFs series were obtained after cool-down to room temperature.

\subsection{Characterizations}

The nitrogen adsorption isotherms of CNFs and ACNFs were measured with BELSORP-max (BEL Japan, Japan) at liquid-nitrogen temperature. All samples were degassed at $300^{\circ} \mathrm{C}$ for $6 \mathrm{~h}$ prior to measurement. The specific surface area was calculated in the relative pressure interval of $0.04-0.2$ using the Brunauer-Emmett-Teller method [18]. Micro size was calculated by the Dubinin-Radushkevich equation from adsorption curves $[19,20]$. The morphology of CNF-800, CNF-850, CNF-900, and CNF-950 were explored using a field-emission scanning electron microscope (JSM 6701-F, JEOL, Japan). To reduce charging during scanning electron microscopy (SEM) imaging, the samples were first placed on a sample holder and coated with platinum. Diameter distributions of the nanofibers were determined by measuring 100 nanofibers from different regions of each SEM image. X-Ray diffraction spectra were obtained using a PHI 5000 VersaProbe II (ULVAC-PHI, Japan) diffractometer with a thin-film attachment. $\mathrm{A} \mathrm{Cu} \mathrm{K} \alpha_{1}$ X-ray source was used at $40 \mathrm{kV}$ and $126 \mathrm{~mA}$.

\subsection{Electrochemical measurements}

The capacitive performance of the as-prepared samples was investigated in $1 \mathrm{M}$ organic electrolyte $\left[1 \mathrm{M}\left(\mathrm{C}_{2} \mathrm{H}_{5}\right)_{4} \mathrm{NBF}_{4} /\right.$ propylene carbonate] solution using a coin-type two-electrode testing cell. The electrodes were prepared by mixing the carbon samples with carboxymethyl cellulose, styrene butadiene rubber, and commercial carbon. The slurries were rolled into a membrane and then pressed onto Al-mesh current collectors. Thereafter, the electrodes were dried at $120^{\circ} \mathrm{C}$ for $24 \mathrm{~h}$ in an oven. Each electrode was fabricated by pressing the ACNF-coated film between two circular pieces of $\mathrm{Al}$ mesh. A two-electrode configuration was used to measure electrochemical performance.

The fifth cycle of galvanostatic charge/discharge was used to evaluate the electrochemical performance of the samples. The specific capacitance was calculated from data generated during the charge/discharge tests, based on the following equation:

$$
C_{g}=\mathrm{i} \Delta \mathrm{t} / \mathrm{m} \Delta \mathrm{V}
$$

where $\mathrm{i}$ is the discharge current $(\mathrm{A}), \Delta \mathrm{t}$ is the discharge time $(\mathrm{s}), \mathrm{m}$ is the mass of electrode $(\mathrm{g})$, and $\Delta \mathrm{V}$ is the potential difference $(\mathrm{V})$.

\section{Results and Discussion}

\subsection{Surface morphology analysis}

The microstructure of the prepared CNFs is shown in Fig. 1. The surfaces of all the CNFs were typically very smooth, without any pores, but with some uneven surfaces. The average diameter of the CNFs obtained from this experiment was estimated by ImageJ software (JEOL, Japan), installed in the SEM apparatus. As can be seen in Fig. 2, the PAN nanofibers diameter is relatively uniform $(710 \mathrm{~nm})$. The diameters of the PAN nanofibers decreased slightly during carbonization. Fig. $2 b$ shows CNF-800: the average diameter of fibers being around $670 \mathrm{~nm}$. The diameter of the CNFs decreased with increasing carbonization temperature. It was found that the diameter of the fibers decreased to around $640 \mathrm{~nm}$ as a result of carbonization at the temperature of $950^{\circ} \mathrm{C}$.

\subsection{Chemical composition}

The chemical composition of the CNFs carbonized at different activation temperatures were evaluated by X-ray photoelectron spectroscopy elemental analysis and listed in Table 1. The carbon content was determined to be $84.28,85.44$, 87.48 , and $89.13 \%$ for the CNFs samples carbonized at 800 , 850,900 and $950^{\circ} \mathrm{C}$, respectively. It was found that the carbon content of the CNFs decreased with increasing carbonization temperature. High carbonization temperature results in a greater amount of volatiles being released from the raw material.

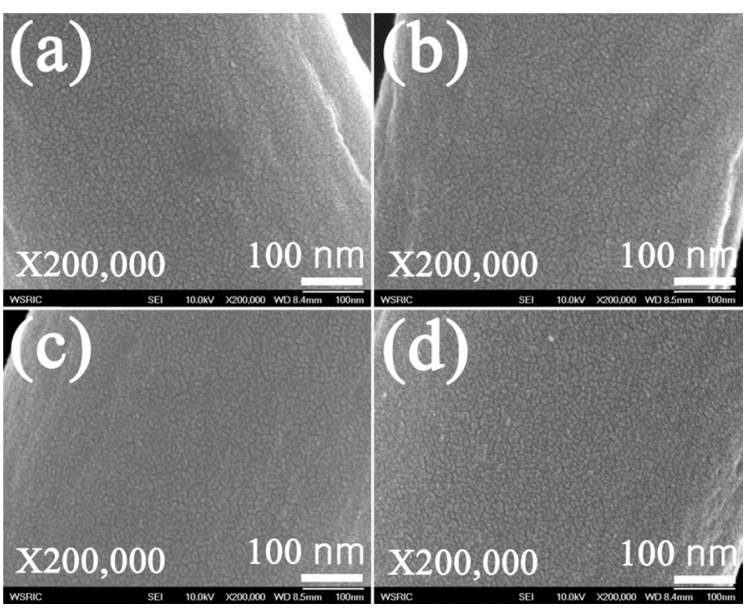

Fig. 1. Scanning electron microscopy micrographs of carbon nanofibers (CNFs) carbonized at different temperatures: (a) CNF-800, (b) CNF850, (c) CNF-900, and (d) CNF-950. 

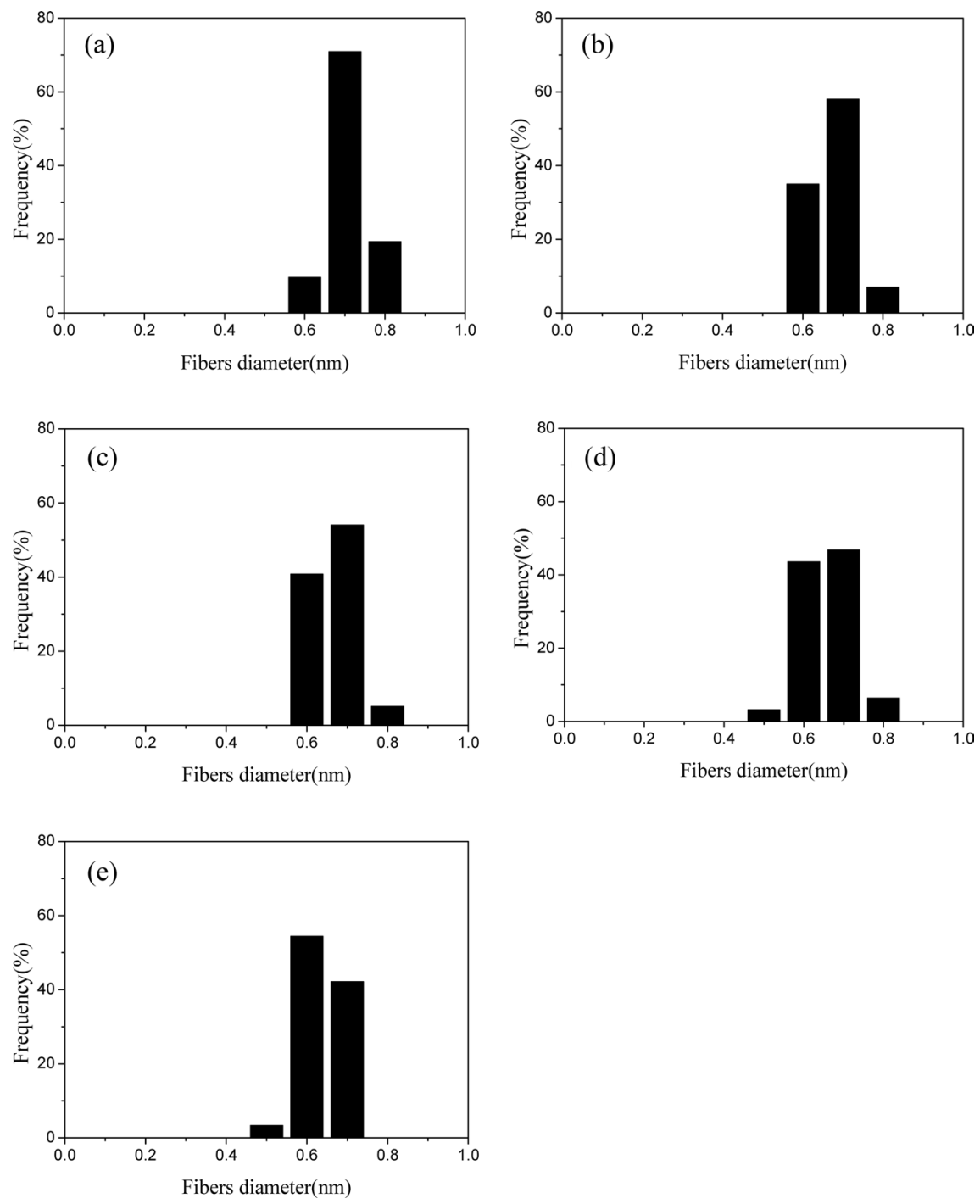

Fig. 2. Diameter distribution of carbon nanofibers (CNFs) carbonized at different temperatures: (a) polyacrylonitrile nanofibers, (b) CNF-800, (c) CNF-850, (d) CNF-900, and (e) CNF-950.

Table 1. XPS chemical composition of CNFs carbonized at different temperatures

\begin{tabular}{cccc} 
& $\mathrm{C}(\%)$ & $\mathrm{O}(\%)$ & $\mathrm{N}(\%)$ \\
\hline CNF-800 & 84.28 & 4.70 & 10.36 \\
CNF-850 & 85.44 & 7.04 & 5.66 \\
CNF-900 & 87.48 & 6.77 & 4.67 \\
CNF-950 & 89.13 & 4.94 & 4.36 \\
\hline
\end{tabular}

XPS: X-ray photoelectron spectroscopy, CNFs: carbon nanofibers.

\subsection{Textural properties and pore structure}

The specific surface area and pore structures of the ACNFs before and after activation are shown in Table 2 . The specific surface area of the CNFs increased with $\mathrm{H}_{2} \mathrm{O}$ activation. The specific surface area of CNFs decreased with increasing carbonization temperature. If the carbonization temperature was increased, the specific surface area increased to equal that of ACNF-850 (electrode carbonized at $850^{\circ} \mathrm{C}$ ) and then decreased. Total pore-volume showed a similar trend. The ACNF-900 sample showed better-developed mesopores than did the ACNF-850 and ACNF-950 samples. This means that a moderate carbonization temperature results in larger pore size.

It is clear that the surface area and pore structure are significantly influenced by the carbonization temperature. The specific surface area of the ACNFs varied between 850 and $1710 \mathrm{~m}^{2} / \mathrm{g}$. It reached a maximum value of $1710 \mathrm{~m}^{2} / \mathrm{g}$ at $850^{\circ} \mathrm{C}$, indicating that moderate carbonization is beneficial for obtaining high-surfacearea ACNFs.

The manufacture of ACNFs by $\mathrm{H}_{2} \mathrm{O}$ activation involves two steps: carbonization of the precursor under an inert gas, and activation of carbonized webs in $\mathrm{H}_{2} \mathrm{O}$. In the carbonization step, the resulting char becomes rich in carbon and the fundamental 
Table 2. Textural properties of ACNFs and CNFs carbonized at different temperatures

\begin{tabular}{cccccc} 
& $\begin{array}{c}\mathrm{S}_{\text {BET }} \\
\left(\mathrm{m}^{2} / \mathrm{g}\right)\end{array}$ & $\begin{array}{c}\mathrm{V}_{\text {Total }} \\
\left(\mathrm{cm}^{3} / \mathrm{g}\right)\end{array}$ & $\begin{array}{c}\mathrm{V}_{\text {Meso }} \\
\left(\mathrm{cm}^{3} / \mathrm{g}\right)\end{array}$ & $\begin{array}{c}\mathrm{V}_{\text {Micro }} \\
\left(\mathrm{cm}^{3} / \mathrm{g}\right)\end{array}$ & $\begin{array}{c}\mathrm{C}_{\mathrm{g}} \\
(\mathrm{F} / \mathrm{g})\end{array}$ \\
\hline CNF-800 & 230 & 0.22 & 0.12 & 0.10 & 0.5 \\
CNF-850 & 200 & 0.33 & 0.25 & 0.08 & 1.6 \\
CNF-900 & 60 & 0.09 & 0.07 & 0.02 & 0.4 \\
CNF-950 & 40 & 0.08 & 0.06 & 0.02 & 0.7 \\
ACNF-800 & 850 & 0.64 & 0.31 & 0.33 & 16.5 \\
ACNF-850 & 1710 & 0.82 & 0.24 & 0.58 & 19.5 \\
ACNF-900 & 1560 & 0.89 & 0.34 & 0.55 & 24.2 \\
ACNF-950 & 1110 & 0.72 & 0.31 & 0.41 & 28.1 \\
\hline
\end{tabular}

ACNFs: activated carbon nanofibers, BET: Brunauer-Emmett-Teller.

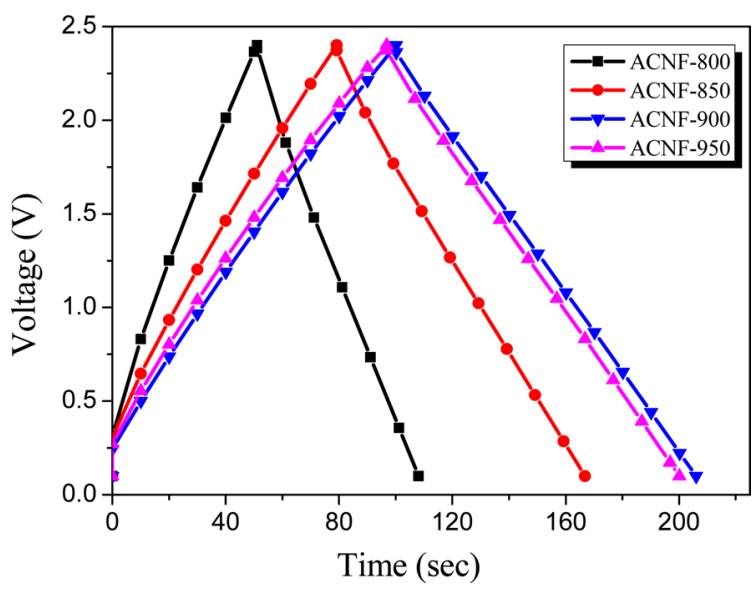

Fig. 3. Charge/discharge curves of activated carbon nanofibers (ACNFs) carbonized at different temperatures.

porous structure is generated by eliminating non-carbon atoms. Meanwhile, the microcrystalline structure of the char is rearranged, resulting in a well-ordered structure. This rearrangement hinders the subsequent activation reaction. For these reasons, carbonization cannot be accomplished at a low temperature. On the other hand, carbonization at a high temperature may make the structure of the carbonized webs too well-ordered to be easily gasified.

\subsection{Electrochemical characterizations}

The electrochemical properties of the ACNF electrodes, including galvanostatic charge/discharge, were studied using propylene carbonate solution as electrolyte. Fig. 3 shows typical galvanostatic charge/discharge curves, of the specific capacitance in relation to current density, of ACNF electrodes carbonized at various temperatures. Based on the results of chargedischarge cycling, the specific discharge capacitance increased with increasing mesopore volume. The curves are almost linear and discharge time gradually increases with increasing carbonization temperature. The specific capacitance of the samples carbonized at temperatures of $800,850,900$ and $950^{\circ} \mathrm{C}$; is about $16.5,19.5,24.2$ and $28.1 \mathrm{~F} / \mathrm{g}$, respectively. Normally, the specific capacitance of the ACNFs exhibits a strong relationship with their mesoporosity

\section{Conclusions}

In this work, ACNF electrodes with high double-layer capacitance and good rate capability were prepared from PAN nanofibers by optimizing the carbonization temperature prior to $\mathrm{H}_{2} \mathrm{O}$ activation. The carbonization temperature has a marked effect on the specific surface area, the pore volume, and the electrochemical performance of ACNFs. An increase of the carbonization temperature induces higher specific surface area and larger pore size, which result in higher capacitance and better rate capability. From the charge-discharge characteristics, ACNF950 showed the best result $(28.1 \mathrm{~F} / \mathrm{g})$, among all the activated samples.

\section{Acknowledgments}

This study was supported by a grant from the Carbon Valley R\&D Project (Project No. R0002651) and Honam Institute for Regional Program Evaluation through the Leading Industry Development for Economic Region funded by the Ministry of Trade, Industry \& Energy (MOTIE), Republic of Korea.

\section{References}

[1] Winter M, Brodd RJ. What are batteries, fuel cells, and supercapacitors? Chem Rev, 104, 4245 (2004). http://dx.doi.org/10.1021/ cr020730k.

[2] Zhang LL, Zhao XS. Carbon-based materials as supercapacitor electrodes. Chem Soc Rev, 38, 2520 (2009). http://dx.doi. org/10.1039/B813846.

[3] Xiang C, Li M, Zhi M, Manivannan A, Wu N. Reduced graphene oxide/titanium dioxide composites for supercapacitor electrodes: shape and coupling effects. J Mater Chem, 22, 19161 (2012). http://dx.doi.org/10.1039/C2JM33177B.

[4] Watson VJ, Nieto Delgado C, Logan BE. Influence of chemical and physical properties of activated carbon powders on oxygen reduction and microbial fuel cell performance. Environ Sci Technol, 47, 6704 (2013). http://dx.doi.org/10.1021/es401722j.

[5] Lei C, Amini N, Markoulidis F, Wilson P, Tennison S, Lekakou C. Activated carbon from phenolic resin with controlled mesoporosity for an electric double-layer capacitor (EDLC). J Mater Chem A, 1, 6037 (2013). http://dx.doi.org/10.1039/C3TA01638B.

[6] Liang P, Yuan L, Yang X, Zhou S, Huang X. Coupling ion-exchangers with inexpensive activated carbon fiber electrodes to enhance the performance of capacitive deionization cells for domestic wastewater desalination. Water Res, 47, 2523 (2013). http:// dx.doi.org/10.1016/j.watres.2013.02.037.

[7] Ye H, Yuan Z, Li S, Zhang L. Activated carbon fiber cloth and $\mathrm{CaCl} 2$ composite sorbents for a water vapor sorption cooling sys- 
tem. Appl Therm Eng, 62, 690 (2014). http://dx.doi.org/10.1016/j. applthermaleng.2013.10.035.

[8] Huang L, Zhou S, Jin F, Huang J, Bao N. Characterization and mechanism analysis of activated carbon fiber felt-stabilized nanoscale zero-valent iron for the removal of $\mathrm{Cr}(\mathrm{VI})$ from aqueous solution. Colloids Surf Physicochem Eng Aspects, 447, 59 (2014). http://dx.doi.org/10.1016/j.colsurfa.2014.01.037.

[9] Zhang J, Nakai T, Uno M, Nishiki Y, Sugimoto W. Effect of the boron content on the steam activation of boron-doped diamond electrodes. Carbon, 65, 206 (2013). http://dx.doi.org/10.1016/j. carbon.2013.08.015.

[10] González PG, Pliego-Cuervo YB. Physicochemical and microtextural characterization of activated carbons produced from wate steam activation of three bamboo species. J Anal Appl Pyrolysis, 99, 32 (2013). http://dx.doi.org/10.1016/j.jaap.2012.11.004.

[11] Xiao J, Liu Z, Kim K, Chen Y, Yan J, Li Z, Wang W. S/O-functionalities on modified carbon materials governing adsorption of water vapor. J Phys Chem C, 117, 23057 (2013). http://dx.doi. org/10.1021/jp408716e.

[12] Kim JM, Song IS, Cho D, Hong I. Effect of carbonization temperature and chemical pre-treatment on the thermal change and fiber morphology of kenafbased carbon fibers. Carbon Lett, 12, 131 (2011). http://dx.doi.org/10.5714/CL.2011.12.3.131.

[13] Hassan AF, Youssef AM. Preparation and characterization of microporous $\mathrm{NaOH}$-activated carbons from hydrofluoric acid leached rice husk and its application for lead(II) adsorption. Carbon Lett, 15, 57 (2014). http://dx.doi.org/10.5714/CL.2014.15.1.057.
[14] Bhati S, Mahur JS, Dixit S, Chobey ON. Study on effect of chemical impregnation on the surface and porous characteristics of activated carbon fabric prepared from viscose rayon. Carbon Lett, 15, 45 (2014). http://dx.doi.org/10.5714/CL.2014.15.1.045.

[15] Falco C, Marco-Lozar JP, Salinas-Torres D, Morallón E, CazorlaAmorós D, Titirici MM, Lozano-Castelló D. Tailoring the porosity of chemically activated hydrothermal carbons: influence of the precursor and hydrothermal carbonization temperature. Carbon, 62, 346 (2013). http://dx.doi.org/10.1016/j.carbon.2013.06.017.

[16] Xu B, Wu F, Chen S, Zhang C, Cao G, Yang Y. Activated carbon fiber cloths as electrodes for high performance electric double layer capacitors. Electrochim Acta, 52, 4595 (2007). http://dx.doi. org/10.1016/j.electacta.2007.01.006.

[17] Yang X, Wu D, Chen X, Fu R. Nitrogen-enriched nanocarbons with a 3-D continuous mesopore structure from polyacrylonitrile for supercapacitor application. J Phys Chem C, 114, 8581 (2010) http://dx.doi.org/10.1021/jp101255d.

[18] Brunauer S, Emmett PH, Teller E. Adsorption of gases in multimolecular layers. J Am Chem Soc, 60, 309 (1938). http://dx.doi org/10.1021/ja01269a023.

[19] Dubinin MM. Generalization of the theory of volume filling of micropores to nonhomogeneous microporous structures. Carbon, 23 , 373 (1985). http://dx.doi.org/10.1016/0008-6223(85)90029-6.

[20] Dubinin MM. On methods for estimating micropore parameters of carbon adsorbents. Carbon, 26, 97 (1988). http://dx.doi. org/10.1016/0008-6223(88)90014-0. 